\title{
SOCIEDADE TECNOLOGICA: A INFORMAÇÃO E O \\ CONSUMO COMO REFLEXOS DA MODERNIDADE
}

SOCIETY OF TECHNOLOGY: INFORMATION AND CONSUMPTION AS REFLECTIONS OF MODERNITY

LA SOCIEDAD TECNOLÓGICA: LA INFORMACIÓN Y EL CONSUMO COMO REFLEJOS DE LA MODERNIDAD

\author{
Agostinho Oli Koppe Pereira ${ }^{1}$ \\ Fabiana Barcelos da Silva² \\ Jerônimo Giron ${ }^{3}$
}

1 Professor no Mestrado em Direito Ambiental da Universidade de Caxias do Sul/RS - Brasil. Orientador e Professor-Coordenador do Grupo de Pesquisa Metamorfose Jurídica. Professor. E-mail: agostinhokp@uol.com.br.

2 Mestranda em Direito Ambiental pela Universidade de Caxias do Sul/RS - Brasil. Bolsista CAPES-Prosup II. Linha de Pesquisa: Novos Direitos e Direito Ambiental. Graduada em Direito pela Universidade Regional Integrada do Alto Uruguai e das Missões - Campus Santiago. Participante do Grupo de Pesquisa Metamorfose Jurídica. Atuação: Analista Jurídico. E-mail: fabi.barcelos.jus@gmail.com

3 Mestrando em Direito Ambiental pela Universidade de Caxias do Sul/RS - Brasil. Bolsista CAPES-Prosup II. Linha de Pesquisa: Novos Direitos e Direito Ambiental. Graduado em Direito pela UCS. Participante do Grupo de Pesquisa Metamorfose Jurídica. Atuação: Advogado. E-mail: giron.jus@gmail.com 
Resumo: Este trabalho avalia as discussões conceituais que circundam alguns debates do meio acadêmico, dentre os quais sobre o momento social em que se vive: na modernidade ou na pós-modernidade? Evidencia que existem divergências, mas que os teóricos são unânimes em ponderar que a ciência e a técnica imperam como marcos caracterizados desses movimentos. Concomitantemente, reflete-se sobre as características da modernidade/pós-modernidade e sobre a ascensão do uso de novas tecnologias, em especial do computar - Internet, meios de comunicação - e a interação de tal instrumento com o consumo. Por fim, retrata que, atualmente, em diversos países, há a eclosão da sociedade de consumo e que pela interação dos agentes dessa sociedade com as perspectivas consumeristas e tecnológicas, o direito deverá se adequar para compatibilizar a defesa dos direitos das pessoas afetadas pelos efeitos negativos de tal interação.

Palavras-chave: Tecnologia. Informação. Consumo. Modernidade.

Abstract: This work evaluates the conceptual discussions surrounding some academic debates, among which is the social environment in which we live: modernity or post-modernity? It shows that there are divergences, but that thinkers are unanimous in considering that science and technique are key elements this movement. Concomitantly, it reflects on the characteristics of the modernity/post-modernity, and the rise of the use of new technologies, particularly the computer - Internet, media - and it's interaction with consumption. Finally, it demonstrates that recently, in many countries, there has been an outbreak of the consumer society and which through the interaction of the agents of this society with the consumerist and technological perspectives, the right should be adapted to ensure the defense of the rights of those affected by the negative effects of this interaction. 
Key Words: Technology. Information. Consumption. Modernity.

Resumen: Este trabajo evalúa las discusiones conceptuales que circundan algunos debates del medio académico, entre ellos sobre el momento social en que se vive: en la modernidad o en la posmodernidad? Evidencia que existen divergencias, pero que los teóricos son unánimes en considerar que la ciencia y la técnica imperan como marcos caracterizados de esos movimientos. Al mismo tiempo, se reflexiona acerca de las características de la modernidad/posmodernidad y sobre la ascensión del uso de nuevas tecnologías, en especial del computar - Internet, medios de comunicación - y la interacción de tal instrumento con el consumo. Por último, retrata que actualmente, en diversos países, se registra una eclosión de la sociedad de consumo y que por la interacción de los agentes de esa sociedad con las perspectivas consumeristas y tecnológicas, el derecho deberá adecuarse para compatibilizar la defensa de los derechos de las personas afectadas por los efectos negativos de tal interacción.

Palabras clave: Tecnología. Información. Consumo. Modernidad.

\section{INTRODUÇÃO}

\section{T sociedade é um corpo coletivo. Na pré-modernidade esta poderia ser reduzida e entendida como comunidade. Na modernidade/ 1 pós-modernidade ela aparece adjetivada: sociedade da informação, sociedade de consumo.}

Cada uma das sociedades citadas possui peculiaridades próprias, contudo, elas se permeiam, visto que não existe apenas uma sociedade dita de consumo, ou da informação: trata-se de uma amálgama que é regida por interesses/fatores 
maiores: economia, política... De qualquer maneira, teóricos tentam explicar sociólogos, filósofos, antropólogos, entre outros - por meio de argumentos conceituais e/ou explicações pragmáticas as possíveis interações sociais que tais sociedades provocam.

Tendo em vista a eclosão de diversas discussões conceituais acerca do advento da modernidade ou pós-modernidade, esta comunicação almeja navegar por canais teóricos com o objetivo de verificar qual é a consideração de diversos pensadores vinculados à seara sociológica/filosófica sobre tais perspectivas.

Adotando por método o hermenêutico e a leitura de bibliografias correlacionadas ao tema em análise - modernidade/pós-modernidade, consumo, informação e tecnologia -, incursiona-se pela fluidez de Bauman; passeia-se pela descontinuidade de Giddens; chegando-se à sociedade de consumo de Baudrillard; expondo, dessa forma, alguns fatores extrínsecos que interferem na constituição de algumas interações sociais no Brasil, especialmente o consumo e as suas consequências.

Além disso, verifica-se a relação existente entre as novas tecnologias e o consumo, em especial com o computador, com especial atenção à Internet, uma vez que, por meio dela, reelaborou-se o contexto tempo/espaço, tendo em vista o desenvolvendo de ferramentas dinâmicas de comunicação que interferem/ estimulam de maneira direta os seres humanos a praticar diversos atos, dentre os quais o de consumo.

Por fim, analisa-se como o direito brasileiro interage com essa realidade pela visualização da legislação de proteção ao consumidor, Código de Proteção e Defesa do Consumidor (CDC), Lei n. ${ }^{\circ}$ 8.078, de 11 de setembro de 1990.

\section{UMA SOCIEDADE MOVEDIÇA}

A sociedade atual, em especial a porção ocidental do planeta, convive com uma realidade socioeconômica ágil e mutante. Computadores, telefones celulares, dispositivos androides, autoestradas, instantaneidade da comunicação, são algumas das características dessa nova perspectiva que floresce diuturnamente. Constatase que parte das relações humanas está alicerçada sobre a base da efemeridade ${ }^{4}$.

4 "Efêmero. [...] 1. Que dura um só dia. 2. De pouca duração; passageiro, transitório: 'todas 
Expressões como conectividade, interligação, global e virtual se apresentam nos diálogos entre as pessoas. Parece que uma Nova Era se consolida.

Aliado a essa nova possibilidade de concepção social, desponta a globalização. Ela, como processo, implica profundas mudanças no campo econômico, político, sociocultural e tecnológico, as quais potencializam diversas discussões, dentre as quais a que se refere ao momento histórico-social que a sociedade se encontra.

A globalização atual é muito menos um produto das ideias atualmente possíveis e, muito mais, o resultado de uma ideologia restritiva adrede estabelecida. Já vimos que todas as realizações atuais, oriundas de ações hegemônicas, têm como base construções intelectuais fabricadas antes mesmo da fabricação das coisas e das decisões de agir. A intelectualização da vida social, recentemente alcançada, vem acompanhanda de uma forte ideologização. ${ }^{5}$

Diversos pensadores, especialmente sociólogos, teorizam sobre essa situação: seria a consolidação da modernidade ou da pós-modernidade. Dessa forma, cabe analisar o que alguns deles propõem, para assim tentar chegar a um ponto de convergência, qual seja: independentemente de estar na pré, durante ou pósmodernidade, existem fatores que interferem diretamente na vida dos seres humanos: trata-se da ciência e da técnica.

Anthony Giddens, autor britânico, desenvolve uma análise profunda sobre a modernidade. Pare ele,

[...] "modernidade" refere-se a estilo, costume de vida ou organização social que emergiram na Europa a partir do século XVII e que ulteriormente se tornaram mais ou menos mundiais em sua influência. Isto associa a modernidade a um período de tempo e a uma localização geográfica inicial, mas por enquanto deixa suas características principais guardadas em segurança numa caixa preta. Hoje, no final do século $X X$, muita gente argumenta que estamos no limiar de uma nova era, a qual as ciências sociais devem responder e que está nos levando para

as formas se mudam, decaem e perecem ou se transformam, são todas efêmeras e caducas, ao passo que a idéia ou substância é sempre viva, verde e eternal' (João Ribeiro, Páginas de Estética, p. 87). [...]" FERREIRA, Aurélio Buarque de Holanda. Novo Dicionário da Língua Portuguesa. 1. ed. 8. impr. Rio de Janeiro: Nova Fronteira, s/a, p. 500.

5 SANTOS, Milton. Por uma outra globalização - do pensamento único à consciência universal. 19. ed. Rio de Janeiro: Record, 2010, p. 159. 
além da própria modernidade. Uma estonteante variedade de termos tem sido sugerida para esta transição, alguns dos quais se referem positivamente à emergência de um novo tipo de sistema social (tal como a "sociedade de informação" ou a "sociedade de consumo"), mas cuja maioria sugere que, mais que um estado de coisas precedente, está chegando a um encerramento ("pósmodernidade", "pós-modernismo", "sociedade pós-industrial", e assim por diante). Alguns dos debates sobre estas questões se concentram principalmente sobre transformações institucionais, particularmente as que sugerem que estamos nos deslocando de um sistema baseado na manufatura de bens materiais para outro relacionado mais centralmente com informação. ${ }^{6 \text { (Grifo nosso). }}$

Apesar da discussão sobre em qual momento social se encontra, Giddens caracteriza a modernidade como um instante em que a descontinuidade é premente, ou seja, nada é permanente, tudo está em constante movimentação e alteração. Tudo é efêmero. Assim, para o citado autor: "[...] as instituições sociais modernas são, sob alguns aspectos, únicas - diferentes em forma de todos os tipos de ordem tradicional". ${ }^{7}$

A modernidade instituiu uma realidade peculiar à sociedade, especialmente por ter alterado, quase que por completo, as perspectivas que outrora foram erigidas na pré-modernidade. Para Pereira, "O termo 'modernidade', como hoje é entendido, remonta ao iluminismo. Era o momento pós-Medievo que se estabelecia com bases bem consolidadas na razão. A modernidade traz idéias novas para a sociedade, buscando romper com as sociedades tradicionais e retirando a ênfase no passado, característica deste tipo de sociedade, para se voltar para o futuro, para o novo". ${ }^{8}$

Percebe-se que a modernidade erigiu uma ruptura com a tradição, pois se apresentou como oposição à autoridade da fé, por meio da imposição da razão humana e da valorização do indivíduo, livre e autônomo, em oposição às instituições.

6 GIDDENS, Anthony. As conseqüências da modernidade. Tradução de Raul Fiker. - São Paulo: Editora UNESP, 1991, p.08.

7 GIDDENS, Anthony. As conseqüências da modernidade. pp. 9-10.

8 PEREIRA, Agostinho Oli Koppe; PEREIRA, Henrique Mioranza Koppe. Relação de Consumo e Modernidade: conseqüências desta interação sobre os riscos ao meio ambiente. In: PILAU SOBRINHO, Liton (Org.). Balcão do Consumidor. Passo Fundo: Ed. Universidade de Passo Fundo, 2010, p. 70. 
A dúvida metódica conduz Descartes a um primeiro conjunto de verdades: "Eu duvido, isso é certo. Se duvido, é porque eu penso, isso também é certo. Se eu penso, eu existo: é certo que eu existo porque eu penso". [...] Cogito, ergo sum, isto é, "Penso, logo existo": eis a primeira certeza cartesiana, da qual é possível ter-se uma ideia clara e distinta. $O$ Cogito cartesiano ("eu penso") fundamenta a possibilidade da ciência: admitem-se como verdade apenas ideias claras e distintas. A evidência racional é o critério que deve guiar todo ser humano na construção do conhecimento. Assim, é possível perceber a ênfase no sujeito conhecedor - todo conhecimento resulta exclusivamente do próprio ato de pensar. ${ }^{9}$

Tudo isso permite compreender que a ideia da racionalidade pode ser vista como a crença no poder crítico da razão humana individual representada pela ideia da busca de progresso. Assim, se as instituições medievais (Igreja) e o conhecimento antigo (Aristóteles) não dão conta de justificar a ciência moderna, a opção encontrada por Descartes foi a interioridade do homem, ou seja, a justificação pela razão humana.

Dessa forma, a descontinuidade, o efêmero, o rompimento são algumas das características atribuídas à modernidade. Autores, como Canclini, defendem a tese de que se está aportando sobre um novo contexto. Chega-se à pós-modernidade.

[...] as identidades modernas eram territoriais e quase sempre monolinguísticas. Consolidaram-se subordinando regiões e etnias dentro de um espaço mais ou menos arbitrariamente definido, chamado de nação [...]. Ao contrário, as identidades pós-modernas são transterritoriais e multilinguísticas. Estruturam-se menos pela lógica dos Estados do que pela dos mercados; [....$^{10}$

A modernidade proporcionou uma reflexão sobre a noção de tempo e de espaço. A luz solar deixou de ser parâmetro. Os quilômetros foram aniquilados. As novas tecnologias deixam de ser novidade para ser entendidas, paradoxalmente, como obsoletas.

\section{A sociedade que entra no século XXI não é menos "moderna" que a que entrou no século $X X ; 0$ máximo que se pode dizer é que}

9 SOUZA, Sonia Maria Ribeiro de. Um outro olhar - Filosofia. Editora FTD, SP, 1995, p.7475.

10 CANCLINI, Néstor García. Consumidores e Cidadãos. 7. ed. Rio de Janeiro: Editora da UFRJ, 2008, pp. 45-46. 
ela é moderna de um modo diferente. O que a faz tão moderna como era mais ou menos há um século é o que distingue a modernidade de todas as outras formas históricas do convívio humano: a compulsiva e obsessiva, contínua e irrefreável e sempre incompleta modernização; a opressiva e inerradicável, insaciável sede de destruição criativa (ou de criatividade destrutiva, se for o caso: de "limpar o lugar" em nome de um "novo e aperfeiçoado" projeto; de "desmantelar", "cortar", "defasar", "reunir" ou "reduzir", tudo isso em nome da maior capacidade de fazer o mesmo no futuro - em nome da produtividade ou da competitividade). ${ }^{11}$ (Grifo nosso).

Um dos exemplos dessa reelaboração do tempo/espaço está no cartão de crédito. Ele é o instrumento de libertação, uma vez que não existe o vínculo com cheque e dinheiro e ainda se outorga prazo para o pagamento!

Claro está, o centro instaurou, para quem assim o desejar, o modo mais moderno de pagamento: $0<<$ cartão de crédito >> . Liberta do cheque, do dinheiro líquido... e até dos fins dos meses difíceis. Doravante, para pagar, basta mostrar o cartão e assinar a factura. É tudo. Todos os meses receberá uma lista das contas que pode pagar de uma só vez ou por prestações mensais. ${ }^{12}$

Aliado a tudo isso, vê-se que, além da discussão conceitual, existem interações concretas e fatos que caracterizam a sociedade hodierna. Essas zonas de contato dão-se pelas tecnologias - cartão de crédito, Internet, telefone celular -, pela ciência, mas especialmente pelo consumo, que atualmente motiva o avanço e o desenvolvimento daqueles.

Por conseguinte, nota-se que existe um debate acadêmico exacerbado sobre em qual momento histórico a sociedade se encontra. Todavia, há relativo consenso de que a técnica e a ciência imperam nesse buraco negro. ${ }^{13}$

11 CANCLINI, Néstor García. Consumidores e Cidadãos. p. 36.

12 BAUDRILLARD, Jean. A Sociedade de Consumo. Lisboa/PT: Edições 70, 2010, p. 20.

13 "A modernidade prima pela técnica e pela ciência. Desenvolver é a palavra de ordem. E esse desenvolvimento técnico, que leva ao progresso tecnológico, caracteriza-se como autônomo, ou seja, a produção de bens da sociedade moderna se realiza sem a necessidade de uma observação política." PEREIRA, Agostinho Oli Koppe; PEREIRA, Henrique Mioranza Koppe. Relação de Consumo e Modernidade: conseqüências desta interação sobre os riscos ao meio ambiente. p. 76. 


\section{DO COMPUTADOR AO CONSUMO, INTERAÇÕES CONCRETAS}

Como acima descrito, atribui-se a busca da verdade à ciência - metodologia científica -, ao contrário da concepção religiosa que outrora tal busca era confiada. Sabe-se que a razão possibilitou o desenvolvimento da ciência. Esta, no mundo da modernidade/pós-modernidade, foi/é uma das válvulas propulsoras das transformações do conhecimento humano, aprimorando a técnica para além da concepção de instrumentos facilitadores do trabalho.

A tecnologia se apresenta como um dos principais constituintes do mundo contemporâneo. Como exemplo dessa construção tecnológica, tem-se a tecnologia da informação, com destaque para o computador. Ele pode ser considerado o instrumento de maior relevância das inovações oriundas da razão humana. Ao arrepio da razão, a sociedade moderna cria meios que se tornaram mais importantes que os fins.

O uso do computador tem uma história recente, não mais que sessenta anos. Contudo, a gênese do desenvolvimento dos computadores reporta-se ao tempo em que o homem usou, pela primeira vez, os dedos para representar quantidade.

Nos séculos XVI e XVII encontra-se a primeira máquina para tratar os números. Foi construída por Wilhelm Schickard (1592-1635) e fazia soma, subtração e divisão. Durante a Guerra dos Trinta Anos, essa máquina foi perdida e ficou a cargo de Blaise Pascal (1623-1662) a construção da primeira calculadora, denominada Pascaline, que somente fazia soma e subtrações. Este projeto foi posteriormente aprimorado por Gottfried Nilhem Leibinz (1646-1716).

Com o advento da Revolução Industrial, as máquinas de calcular sofrem novo impulso. Por intermédio das habilidades de Charles Babbage (1792-1871), professor de matemática, que aprimorou as ferramentas de calcular anteriores, surge o Calculador Analítico.

Larry Gonick escreve sobre o Calculador Analítico de Babbage, evidenciando as principais características do instrumento: 
[...] o moinho, uma roda dentada, no coração da máquina, que seria uma enorme "mastigadora de números" com a capacidade de somar com precisão de até 50 casas decimais. As instruções seriam lidas em cartões perfurados que transportavam não só os números, mas também o padrão de moagem. Ele imaginou ainda uma unidade de memória ou Armazém, onde os números seriam guardados para referencias futuras. "Esta unidade seria um Banco de 100 registradores, cada um deles capaz de armazenar um número de 50 dígitos, que poderiam ser tanto números de cartões de entrada, como os resultados das operações de moinho [...]". ${ }^{14}$

Babbage ficou conhecido como o pai do computador, pelo motivo de seu calculador analítico ser muito parecido com o que se conhece hoje por computador. Por falta de financiamento, Babbage morreu sem concluir o seu invento.

A partir de então, a evolução técnica para os aparelhos que hoje habitam a maioria dos lares do planeta - microcomputadores - foi célere, sendo potencializado a partir da Segunda Guerra Mundial.

Esse grande desenvolvimento tecnológico, que se dinamiza realmente a partir da Segunda Guerra Mundial, decorreu da necessidade do desenvolvimento de máquinas capazes de efetuar rapidamente cálculos complexos, mas, principalmente, de processar a informação e reunir dados de diferentes origens, postos em forma numérica (binária) e associá-los conforme algoritmos predefinidos. É o início da terceira revolução tecnológica ou da revolução da informação. ${ }^{15}$

Com o aperfeiçoamento do computador e dos softwares surge no mundo a possibilidade de criar, por meio de modelos, um mundo virtual - também designado ciber-espaço. Um mundo de ilusão, criado a partir de simulações de objetos (reais ou não), com o qual o usuário pode interagir. Assim, surgiu o que se conhece como Mundo Virtual, ou seja, uma nova forma das pessoas se relacionarem; um local em que todos se comunicam com todos, sem que exista a presença concreta do ser humano. Sérgio Souza refere-se à realidade virtual:

Denomina-se virtual, porque o que se observa não é real, é um mundo representado por impulsos elétricos, que representam ou até mesmo interagem com as pessoas no momento da comunicação como se ali

14 GONICK, Larry. Introdução ilustrada à computação. São Paulo: Ed. Harper \& Row do Brasil, 1984, p. 53-54.

15 PAESANI, Liliana Minardi. O Direito na Sociedade da Informação. São Paulo: Atlas, 2007, p. XII. 
os interlocutores estivessem. É uma espécie de dimensão a que os seres humanos, em sua forma física, têm sua presença limitada, a não ser quando representados pelos dados transmitidos por instruções dadas ao computador. ${ }^{16}$

Percebe-se, então, que essa realidade virtual tem por finalidade criar um tipo de interface entre o usuário e o computador. Essa afirmação é compreendida melhor depois de observados seus três conceitos, que são a imersão, a interação e a manipulação. Sabe-se que são esses fundamentos que permitem que o usuário interprete seus sentidos nessa simulação com o real. Percebe-se que, por englobar os sentidos humanos, há um grande envolvimento do indivíduo com a máquina, possibilitando novas descobertas e experimentos.

Paralelo a isso, vê-se a Internet. Dela, proliferam os chamados websites que, inicialmente, foram idealizados para o comércio eletrônico, como mecanismos de veiculação da publicidade sobre os produtos.

Não se pode duvidar que a Internet seja uma fonte de informação e de serviços de maior utilidade nos últimos tempos. A rede mundial de computadores proporcionou uma mudança econômica por apresentar facilidades como, por exemplo, a velocidade em que os atos ocorrem e a diminuição das distâncias reconstrução do tempo/espaço.

Atrelada a essas inovações da informática, outras evoluções técnicas foram desenvolvidas, avançando inclusive sobre o corpo humano. O advento da cibernética na biologia molecular é um exemplo. Além das próteses que permitem a locomoção e o conforto a pacientes que possuem ou sofreram limitações nas suas composições físicas, a revolução está na compreensão sobre o conceito de "pós-humano". Nas palavras de Celine Lafontaine: "Apesar de suas origens militares, o ciborgue, esse metade homem, metade máquina e metade homem, metade mulher, encarna o hibridismo de uma verdadeira libertação identitária". ${ }^{17}$

Essa situação apresenta discussões que se insurgem no veio acadêmico e científico, visto que a aplicação dos aprimoramentos tecnológicos tenta 16 SOUSA, Sérgio. Tecnologias de informação. Rio de Janeiro: Ed. Brasport, 2000, p. 153.

17 LAFONTAINE. Celine. O Império Cibernético. Instituto Piaget, 2004, p. 191. 
vencer, inclusive, os limites da própria vida humana. Isso reformulou as perspectivas sociais.

Bauman evidencia que o modelo Fordista transmite de maneira peremptória a modernidade pesada, uma vez que existe o vínculo absoluto entre o capital e trabalho. "[...] O tempo congelado da rotina de fábrica, junto com os tijolos e argamassa das paredes, imobilizava o capital tão eficientemente quanto ao trabalho que este empregava. Tudo isso mudou, no entanto, com o advento do capitalismo de software e de modernidade 'leve'". ${ }^{18}$

Neste período - por meio do uso do software -, o espaço pode ser vencido. O tráfego das informações acontece na velocidade da luz, cancelando-se a distância entre o longe e aqui... As redes sociais reais - pois as redes virtuais são incentivadas, uma vez que não produzem práticas concretas de confronto ao sistema - são periodicamente aniquiladas, não sendo incentivados vínculos concretos, para se evitar questionamentos. "[...] é a velocidade atordoante da circulação, da reciclagem, do envelhecimento, do entulho e da substituição que traz o lucro hoje [...]". ${ }^{19}$

No âmago dessa evolução tecnológica verifica-se o consumo. Baudrillard constata que ele é peça chave para a consolidação do sistema produtivo e cultural: "[...] É preciso afirmar claramente, logo de inicio, que o consumo surge como modo activo de relação (não só com os objetos mas [sic] ainda com a colectividade e o mundo), como modo de atividade sistémica e de resposta global, que serve de base a todo o nosso sistema cultural". ${ }^{20}$

À nossa volta, existe hoje uma espécie de evidência fantástica do consumo e da abundância, criada pela multiplicação dos objectos, dos serviços, dos bens materiais, originando como que uma categoria de mutação fundamental na ecologia da espécie humana. Para falar com propriedade, os homens da opulência não se encontram rodeados, como sempre acontecera, por outros homens, mas mais por objectos. ${ }^{21}$ (Grifo nosso).

18 BAUMAN, Zygmunt. Modernidade Líquida. Tradução Plínio Dentzien. Rio de Janeiro: Jorge Zahar Editor, 2001, p. 135.

19 BAUMAN, Zygmunt. Modernidade Líquida. p. 21.

20 BAUDRILLARD, Jean. A Sociedade de Consumo. p. 09.

21 BAUDRILLARD, Jean. A Sociedade de Consumo. p. 13. 
A tecnologia, em especial o computador, aliado à agilidade da Internet propagandas, facilidade de acesso a dados e informações de diversas partes da Terra, entre outras características - reestruturaram os meios de comunicação, fato que motivou uma readequação social, qual seja: a assimilação do consumismo e da cultura do consumo. Para Lyon, "[...] as novas tecnologias de informação e de comunicação, conquanto em si mesmas não produzam nem a sociedade pós-industrial nem a pósmoderna" 22, contudo, elas estão envolvidas nas transformações sociais modernas, em especial no cultivo do consumismo e nas culturas de consumo.

Nesse caminho, para alguns autores, veem-se sulcos de uma pósmodernidade.

[...] As mudanças no capitalismo e no industrialismo que se seguiram à explosão consumista do pós-guerra nas sociedades avançadas produziram o que Bell chamou de pós-industrialismo. Mas como vimos, essas mudanças são agora consideradas mais significativas à medida que o material e o social se projetam para condições pósmodernas. Assim, a pós-modernização tem a ver com o panorama industrial alterado, com produção móvel, flexível, a convulsão na estrutura ocupacional que coloca os serviços e os assim chamados operários da informação numa maioria, e um mundo comprimido, onde novas tecnologias tornam possíveis não somente novos métodos de produção, mas também diferentes formas de relações. ${ }^{23}$

Como exemplo da assertiva acima, destaca-se a existência do contrato eletrônico. Assim, contrato eletrônico é aquele celebrado por meio de programas de computador ou aparelhos com tais programas que expõem virtualmente a manifestação de vontade das partes envolvidas no negócio jurídico ${ }^{24}$.

$\mathrm{Na}$ Internet, os contratos podem ser elaborados basicamente, por meio de dois meios: através de troca de e-mails, ou mediante o oferecimento de propostas em uma homepage, e a correspondente aceitação da outra parte. Por ele se expressa toda a relação de consumo, ou seja, desde a oferta à aceitação, evidenciando a total credibilidade humana nas relações interativas criadas pela tecnologia.

22 LYON, David. Pós-modernidade. São Paulo: Paulus, 1998, p. 83.

23 LYON, David. Pós-modernidade. pp. 84-85.

24 GLANZ, Semy. Apud, ANDRADE, Ronaldo Alves de. Contrato Eletrônico. São Paulo: Editora Manole, 2004, p. 29. 
Percebe-se que o império tecnológico - mesmo que pendente entre a modernidade e a pós-modernidade - direciona-se para o consumo, potencializando-o. Dessarte, cabe destacar como a tecnologia interage na sociedade de consumo e como o direito enfrenta/assimila tal realidade.

\section{O CONSUMO COMO MARCO SOCIAL}

Teóricos da modernidade/pós-modernidade discutem, na sua essência, mudanças conceituais que interferem na constituição da sociedade. Em face disso, retratam-se possíveis vínculos desse debate conceitual/pragmático com algumas áreas de interação social, em especial com o consumo.

Atualmente, tendo em vista a eminência do capitalismo e a rede criada pela globalização econômica, o consumo se transformou em foco de discussão em diversas searas: do direito penal à medicina; do direito ambiental à administração; da história à antropologia. Logo, percebe-se que a população de diversos países está envolta pela perspectiva da sociedade de consumo.

Ela se estrutura sobre o império dos objetos, principalmente na necessidade de tê-los e de logo eliminá-los para adquirir outros. Consoante Baudrillard, "A sociedade de consumo precisa dos seus objectos para existir e sente, sobretudo, necessidade de os destruir. $\mathrm{O}<<$ uso $>>$ dos objectos conduz apenas ao seu desgaste lento. $O$ valor criado reveste-se de maior intensidade no desperdício violento. Por tal motivo, a destruição permanece como a alternativa fundamental da produção: o consumo não passa de termo intermediário entre as duas". ${ }^{25}$

Além disso, cabe destacar que, para o surgimento da sociedade de consumo, uma reestruturação foi engendrada: "[...] O processo de racionalização das forças produtivas que ocorreu durante o século XIX, no sector da produção, alcança o termo no século $X X$, no sector do consumo. O sistema industrial, depois de socializar as massas como forças de trabalho, deveria ir mais longe para se realizar e as socializar (ou seja, controlá-las) como forças de consumo". ${ }^{26}$ 
Dentre os fatores que influenciam/estimulam a manutenção dessa realidade está a utilização dos meios tecnológicos, em especial pelo melhoramento da comunicação, procurando provocar o que se entende por condicionamento das necessidades.

[...] O tema do condicionamento das necessidades (em especial, através da publicidade tornou-se o tema favorito do discurso acerca da sociedade de consumo. A exaltação da abundância e a grande lamentação relativa às < <necessidades artificiais $>>$ ou $<<$ alienadas $>>$ alimentam juntamente a mesma cultura de massas e até ideologia mais especializada sobre a questão. Em geral, radica na velha filosofia moral e social da tradição humanista. ${ }^{27}$

Assim, mediante estímulos e pelo consentimento, o consumo passa a definir determinadas posturas que as pessoas devem adotar, bem como seu modo de agir. Condicionam-se tantos os entes individuais como os coletivos, sendo o próprio Estado ${ }^{28}$ um dos afetados.

As forças de mercado predominam quando a maioria das decisões tomadas por consumidores e firmas individuais acontece em contextos em que ninguém em particular determina as consequências coletivas. Assim, as forças de mercado se realizam a partir de milhões de decisões tomadas por indivíduos ou firmas que se encontram separados uns dos outros. Então, no sistema de mercado capitalista, a alocação de recursos (energia, matéria-prima, força de trabalho, lixo) tende a ser decidida, não por uma agência central (o Estado), mas por decisões de agentes individuais (consumidores/produtores) que atuam no mercado. ${ }^{29}$

Canclini evidencia que "É inegável que, nas últimas décadas, a intensificação das relações econômicas e culturais com os Estados Unidos impulsiona um modelo de sociedade no qual muitas funções do Estado desaparecem ou são

27 BAUDRILLARD, Jean. A Sociedade de Consumo. p. 81.

28 "O significado do Estado social na sociedade de consumidores, tal como era na sociedade de produtores, é defender a sociedade dos "danos colaterais" que o princípio orientador da vida social iria causar se não fosse monitorado, controlado e restringido. Seu propósito é proteger a sociedade da multiplicação das fileiras de "vítimas colaterais" do consumismo: os excluídos, os proscritos, a subclasse. Sua tarefa é evitar a erosão da solidariedade humana e o desaparecimento dos sentimentos de responsabilidade ética." BAUMAN, Zygmunt. Vida para o Consumo. Tradução Carlos Alberto Medeiros. Rio de Janeiro: Jorge Zahar Editor, 2008, p. 181.

29 LENZI, Cristiano Luis. Sociologia ambiental - risco e sustentabilidade na modernidade. Bauru, SP: Edusc, 2006, p. 65. 
assumidas por corporações privadas, e a participação social é organizada mais através do consumo do que mediante o exercício da cidadania. [...]".30

Nessa sociedade, a reificação de Marx é amplificada. Sutilmente as pessoas, após se tornarem objetos de produção, passam a incorporar a função de artefatos de consumo. ${ }^{31}$ Elas não apenas consomem; elas também são consumidas. "Na sociedade de consumidores, ninguém pode se tornar sujeito sem primeiro virar mercadoria, e ninguém pode manter segura sua subjetividade sem reanimar, ressuscitar e recarregar de maneira perpétua as capacidades esperadas e exigidas de uma mercadoria vendável". ${ }^{32}$ Como mercadorias, os seres humanos passam a refletir como tal.

[...] A sociedade de consumidores desvaloriza a durabilidade, igualando "velho" a "defasado", impróprio para continuar sendo utilizado e destinado à lata de lixo. É pela alta taxa de desperdício, e pela decrescente distância temporal entre o brotar e o murchar do desejo, que o fetichismo da subjetividade se mantém vivo e digno de crédito, apesar da interminável série de desapontamentos que ele causa. A sociedade de consumidores é impensável sem uma florescente indústria de remoção do lixo. Não se espera dos consumidores que jurem lealdade aos objetos que obtêm com a intenção de consumir. ${ }^{33}$

$[\ldots]$

A sociedade de consumo prospera enquanto consegue tornar perpétua a não-satisfação de seus membros (e assim, em seus próprios termos, a infelicidade deles). O método explícito de atingir tal efeito é depreciar e desvalorizar os produtos de consumo logo depois de terem sido promovidos no universo dos desejos dos consumidores. ${ }^{34}$

Entretanto, uma questão se impõe: a legislação pode controlar essa voracidade? O Estado, como se encontra, dilapidado pela eminência mercadológica, possui condições de regulamentar tais fatos?

30 CANCLINI, Néstor García. Consumidores e Cidadãos. p. 13.

31 "[...] O 'consumismo' chega quando o consumo assume o papel-chave que na sociedade de produtores era exercido pelo trabalho. [...]

"De maneira distinta do consumo, que é basicamente uma característica e uma ocupação dos seres humanos como indivíduos, o consumismo é um atributo da sociedade." BAUMAN, Zygmunt. Vida para o Consumo. p. 41.

32 BAUMAN, Zygmunt. Vida para o Consumo. p. 20.

33 BAUMAN, Zygmunt. Vida para o Consumo. p. 31.

34 BAUMAN, Zygmunt. Vida para o Consumo. p. 64. 
[...] A ausência, ou a mera falta de clareza, das normas - anomia - é o pior que pode acontecer às pessoas em sua luta para dar conta dos afazeres da vida. As normas capacitam tanto quanto incapacitam; a anomia anuncia a pura e simples incapacitação. Uma vez que as tropas da regulamentação normativa abandonam o campo de batalha da vida, sobram apenas a dúvida e o medo. ${ }^{35}$

Dessarte, cabe destacar o que a legislação brasileira reflete acerca das práticas de consumo vinculadas a perspectivas tecnológicas.

No corpo da Constituição da República Federativa do Brasil, de 05 de outubro de $1988^{36}$ e no Código de Proteção e Defesa do Consumidor (CDC), Lei n. ${ }^{\circ}$ 8.078, de 11 de setembro de 1990, existem referências implícitas. Contudo, ressalta-se que:

É de significativa importância a inserção da função social da empresa e dos direitos e da defesa dos consumidores no texto constitucional, dada a aplicação maior da principiologia aos microssistemas jurídicos pós-constitucionais, notadamente abertos, viabilizando-se uma maior flexibilidade da atividade jurisdicional ao aplicar o direito ao caso concreto e uma interpretação da norma infraconstitucional mais consentânea com as transformações socioeconômicas subjacentes.

Em outras palavras, a proteção do consumidor como direito fundamental constitucional e não apenas como direito básico inserido na Lei n. $^{\circ}$ 8.078, de 11.9.1990. ${ }^{37}$

Observa-se, que, embora não exista disposição específica regulamentando as novas tecnologias na sociedade de consumo brasileira, o CDC, por interpretação sistemática e teleológica, torna o cidadão sujeito de direito nesse universo moderno/pós-moderno.

Para a proteção dos interesses biopsíquicos do consumidor (privacidade, honra objetiva e subjetiva, identidade, direito moral de autor etc.), por ora se deve buscar a aplicabilidade da lei de proteção ao consumidor

35 BAUMAN, Zygmunt. Modernidade Líquida. p. 28.

36 "A constitucionalização das relações jurídicas concretizada no direito brasileiro por imperativo dos arts. $1^{\circ}$ ao 50 , da $\mathrm{CF} / 88$, aplicáveis a qualquer vínculo interpessoal estabelecido por força da lei ou do acordo de vontades, viabilizou a revalorização da pessoa no direito privado, propugnando-se por sua dignidade como princípio fundamental (art. 10, III, da CF/88)." LISBOA, Roberto Senise. O consumidor na Sociedade da Informação. In: PAESANI, Liliana Minardi. O Direito na Sociedade da Informação. São Paulo: Atlas, 2007, p. 134.

37 LISBOA, Roberto Senise. O consumidor na Sociedade da Informação. p. 135. 
vigente no direito brasileiro, hipótese na qual o aplicador da norma se valerá dos princípios gerais da relação de consumo, bem como da política nacional das relações de consumo (arts. $4^{\circ}$ a $7^{\circ}$ do CDC)..$^{38}$

$[\ldots]$

Logo, vigorará nas relações de consumo pelos meios virtuais o princípio da transparência (art. $4^{\circ}$, caput, do CDC), já aplicado na Resolução da União Europeia, tendo o consumidor o direito à identificação autenticada do fornecedor, assim como do direito às informações necessárias para provar a autenticidade de cada elemento de um negócio jurídico. ${ }^{39}$

O Superior Tribunal de Justiça (STJ) posicionou-se acerca de práticas envolvendo a Internet de maneira a incluir o arcabouço protetivo do CDC às pessoas prejudicadas. ${ }^{40}$

Assim, enquanto se discutem teorias; enquanto imperam elementos caracterizadores de uma sociedade de consumo; e enquanto o Direito observa as interações sociais, indaga-se: "[...] < < Que representa o consumidor no mundo moderno? Nada. Que é que ele poderia ser? Tudo ou quase tudo.

38 LISBOA, Roberto Senise. O consumidor na Sociedade da Informação. p. 140.

39 LISBOA, Roberto Senise. O consumidor na Sociedade da Informação. p. 140.

40 "DIREITO CIVIL E DO CONSUMIDOR. INTERNET. RELAÇÃO DE CONSUMO. INCIDÊNCIA DO CDC. GRATUIDADE DO SERVIÇO. INDIFERENÇA. PROVEDOR DE CONTEÚDO. FISCALIZAÇÃO PRÉVIA DO TEOR DAS INFORMAÇÕES POSTADAS NO SITE PELOS USUÁRIOS. DESNECESSIDADE. MENSAGEM DE CONTEÚDO OFENSIVO. DANO MORAL. RISCO INERENTE AO NEGÓCIO. INEXISTÊNCIA. CIÊNCIA DA EXISTÊNCIA DE CONTEÚDO ILÍCITO. RETIRADA IMEDIATA DO AR. DEVER. DISPONIBILIZAÇÃO DE MEIOS PARA IDENTIFICAÇÃO DE CADA USUÁRIO. DEVER. REGISTRO DO NÚMERO DE IP. SUFICIÊNCIA. 1. A exploração comercial da internet sujeita as relações de consumo daí advindas à Lei no 8.078/90. 2. O fato de o serviço prestado pelo provedor de serviço de internet ser gratuito não desvirtua a relação de consumo, pois o termo "mediante remuneração" contido no art. 30 , $\S 20$, do CDC deve ser interpretado de forma ampla, de modo a incluir o ganho indireto do fornecedor. 3. A fiscalização prévia, pelo provedor de conteúdo, do teor das informações postadas na web por cada usuário não é atividade intrínseca ao serviço prestado, de modo que não se pode reputar defeituoso, nos termos do art. 14 do CDC, o site que não examina e filtra os dados e imagens nele inseridos. 4. O dano moral decorrente de mensagens com conteúdo ofensivo inseridas no site pelo usuário não constitui risco inerente à atividade dos provedores de conteúdo, de modo que não se Ihes aplica a responsabilidade objetiva prevista no art. 927, parágrafo único, do $\mathrm{CC} / 02$. 5. Ao ser comunicado de que determinado texto ou imagem possui conteúdo ilícito, deve o provedor agir de forma enérgica, retirando o material do ar imediatamente, sob pena de responder solidariamente com o autor direto do dano, em virtude da omissão praticada. [...]." ST]. REsp 1193764 / SP-RECURSO ESPECIAL 2010/0084512-0. Órgão Julgador: Terceira Turma. Relator: Min.: Nancy Andrighi. Data do Julgamento: 14 de dezembro de 2010. 
Encontrando-se isolado ao pé de milhões de solitários, está ao sabor de todos os interesses $>>$ ". 41

Por tudo isso, cabe atentar para esses interesses, refletindo acerca da implicação deles sobre a sociedade e quais a perspectivas de alterá-los. Caso contrário, o consumo será entendido como um epifenônemo: elemento acessório, cuja presença não importa na produção de efeitos concretos, pois, embora ele provoque algumas deturpações, passou a ser visto como ato essencial para diversas populações, especialmente as ocidentais ${ }^{42}$, não sendo avaliado como protagonista de influências por parte da modernidade e também como influenciador de novas perspectivas sociais.

\section{CONSIDERAÇÕES FINAIS}

Nesse cenário em que novas configurações sociais eclodem, deve o direito acompanhá-las. Como se aprende nas cadeiras do direito, a lei cristaliza os fatos sociais. Mas como o direito poderá cristalizar algo que é entendido como fluido e móvel? Parece que chegou o momento do Direito, por meio de um raciocíonio luhmanniano, questionar sobre sua atuação.

Lyon indaga se a dependência baseada em novas tecnologias leva além da modernidade. ${ }^{43}$ Canclini, na mesma linha, pondera que se deve estudar como estão acontecendo as relações de continuidade, ruptura e hibridização da sociedade, para dessa forma repensar as identidades e a própria cidadania, buscando uma nova concepção para o direito nessa nova realidade. ${ }^{44}$

Antes de simplesmente creditar à legislação a gênese da resolução de todos os problemas advindos da evolução tecnológica e do incentivo para o consumo, deve-se refletir, especialmente por parte daquelas pessoas que possuem uma condição financeira razoável, o papel que o consumo possui em suas vidas e quais as repercussões dessas práticas sobre a realidade social. ${ }^{45}$

41 BAUDRILLARD, Jean. A Sociedade de Consumo. p. 101.

42 LIPOVETSKY, Gilles. A Sociedade da Decepção. Barueri, SP: Manole, 2007, p. 84.

43 LYON, David. Pós-modernidade. p. 60.

44 CANCLINI, Néstor García. Consumidores e Cidadãos. p. 138.

45 "[...] Deveríamos tomar como divisa esta máxima de sabedoria: aja de tal forma que o consumismo não seja onipresente ou hegemônico, quer em tua vida, quer na dos outros. Por 
Quanto à discussão de se estar em um momento moderno ou pós-moderno, cada um pode pensar da maneira que entender. Lyon referenda a perspectiva pós-moderna; Giddens evidencia a modernidade. Para os adeptos da sociedade da informação, a pós-modernidade é o presente; para os que adotam a perspectiva da sociedade do consumo, encontra-se em um momento moderno. Contudo, pode-se ratificar a ideia de Giddens: o que existe é a radicalização da modernidade. Não se pode dizer que se ingressou em um novo contexto social, uma vez que as instituições da modernidade perduram, ocorreram apenas algumas alterações nas interações entre elas. ${ }^{46}$

A sociedade como corpo coletivo deve decidir qual a relevância que existe no uso abusivo das ferramentas eletrônicas. A falta de reflexão sobre a maneira que se conduz essas ações, segundo Bauman, está provocando a morte social ${ }^{47}$, uma vez que as pessoas relacionam-se mais com os equipamentos eletrônicos do que com outras pessoas. Até o ato de consumir está migrando para o virtual. A loja, símbolo da pré-modernidade, está sendo esquecida.

A Internet, por meio do acesso a redes sociais, é espaço em que não existe nem poder nem controle, trata-se assim de um universo sem amarras. Por tudo isso, o Direito deve atuar como elemento de conciliação nas interações que a modernidade/ pós-modernidade engendra no seio da sociedade de consumo, seja por imposição de novas regulamentações, seja pela reinterpretação dos dispositivos existentes.

\section{REFERÊNCIAS}

BAUDRILLARD, Jean. A Sociedade de Consumo. Lisboa/PT: Edições 70, 2010.

BAUMAN, Zygmunt. Modernidade Líquida. Tradução Plínio Dentzien. Rio de Janeiro: Jorge Zahar Editor, 2001.

quê? Para que não tenha um efeito devastador sobre nossa natureza. Infelizmente, é para isso que tende o ímpeto do consumo, especialmente para as parcelas de população mais marginalizadas, que não têm outro objetivo senão comprar, comprar de novo, e comprar mais. É nesse sentido que o mundo consumista é perigoso: ele amputa as outras potencialidades, as outras dimensões da vida propriamente humana. Nós devemos lutar contra o desgaste e a destruição do hiperconsumismo, que subtrai de cada um a capacidade de se construir, de compreender o mundo, de se superar." LIPOVETSKY, Gilles. A Sociedade da Decepção. p. 82.

46 GIDDENS, Anthony. As conseqüências da modernidade.

47 BAUMAN, Zygmunt. Vida para o Consumo. 
Vida para o Consumo. Tradução Carlos Alberto Medeiros. Rio de Janeiro: Jorge Zahar Editor, 2008.

BRASIL. SUPERIOR TRIBUNAL DE JUSTICA - STJ. REsp 1193764 / SP-RECURSO ESPECIAL 2010/0084512-0. Órgão Julgador: Terceira Turma. Relator: Min.: Nancy Andrighi. Data do Julgamento:14 de dezembro de 2010. Acessado em https://ww2.stj.jus.br/revistaeletronica/Abre_ Documento.asp?sSeq=1029789\&sReg=201000845120\&sData=20110808 \&formato=PDF.

CANCLINI, Néstor García. Consumidores e Cidadãos. 7. ed. Rio de Janeiro: Editora da UFRJ, 2008.

COSTA, Luciano Martins. O mal-estar da globalização. São Paulo: A girafa editora, 2005.

FERREIRA, Aurélio Buarque de Holanda. Novo Dicionário da Língua Portuguesa. 1. ed. 8. impr. Rio de Janeiro: Nova Fronteira, s/a.

GLANZ, Semy. Apud, ANDRADE, Ronaldo Alves de. Contrato Eletrônico. São Paulo, Editora Manole, 2004.

GIDDENS, Anthony. As conseqüências da modernidade. Tradução de Raul Fiker. - São Paulo: Editora UNESP, 1991.

GONICK, Larry. Introdução ilustrada à computação. São Paulo: Ed. Harper \& Row do Brasil, 1984.

LAFONTAINE. Celine. O Império Cibernético. Instituto Piaget, 2004.

LENZI, Cristiano Luis. Sociologia ambiental - risco e sustentabilidade na modernidade. Bauru, SP: Edusc, 2006.

LIPOVETSKY, Gilles. A Sociedade da Decepção. Barueri, SP: Manole, 2007.

LISBOA, Roberto Senise. O consumidor na Sociedade da Informação. In: PAESANI, Liliana Minardi. O Direito na Sociedade da Informação. São Paulo: Atlas, 2007, pp. 113-141.

LYON, David. Pós-modernidade. São Paulo: Paulus, 1998.

PAESANI, Liliana Minardi. O Direito na Sociedade da Informação. São Paulo: Atlas, 2007.

PEREIRA, Agostinho Oli Koppe; PEREIRA, Henrique Mioranza Koppe. Relação de Consumo e Modernidade: conseqüências desta interação sobre os riscos ao meio ambiente. pp. 69-95. In: PILAU SOBRINHO, Liton (Org.). Balcão do Consumidor. Passo Fundo: Ed. Universidade de Passo Fundo, 2010. 
SANTOS, Milton. Por uma outra globalização - do pensamento único à consciência universal. 19. ed. Rio de Janeiro: Record, 2010.

SOUSA, Sérgio. Tecnologias de informação. Rio de Janeiro: Ed. Brasport, 2000.

SOUZA, Sonia Maria Ribeiro de. Um outro olhar - Filosofia. Editora FTD, SP, 1995. 